\title{
Granulomatosis con poliangitis
}

\author{
Alfonso García-Luna, ${ }^{1}$ Víctor Hugo Nez-Esquivel, ${ }^{2}$ Francisco López-Baca, ${ }^{2}$ Jorge Mora-Constantino ${ }^{3}$
}

\section{Resumen}

Antecedente: La granulomatosis con poliangitis (granulomatosis de Wegener) es una enfermedad rara, multisistémica, autoinmune, de etiología desconocida. Sus características primordiales incluyen inflamación granulomatosa necrosante y vasculitis pauciinmune de pequeños y medianos vasos; su prevalencia es de 1 a 9/100,000 habitantes y la edad típica de presentación es entre 35 y 55 años. Como problema multisistémico, puede afectar a cualquier territorio de la economía, aunque tiene predilección por las vías aéreas y riñones. Caso clínico: Femenina de 57 años, con un mes de evolución caracterizada por insuficiencias respiratoria y renal, que requirió intubación y hemodiálisis; su evolución a su ingreso a la $\mathrm{UCl}$ fue mala; mostró resultados de c-ANCA positivos. Fue manejada con rituximab, altas dosis de glucocorticoides y plasmaféresis, con lo que se logró la recuperación de la función respiratoria y renal. Conclusiones: Las manifestaciones de granulomatosis con poliangitis pueden presentarse de manera fulminante; los estudios de imagen de tórax con nódulos granulomatosos cavitados en $50 \%$ aunados a glomerulonefritis necrosante con semilunas y la presencia de c-ANCA (sensibilidad de 96 a 98\%) apoyan el diagnóstico, que se confirma con biopsia. El tratamiento actual con rituximab, glucocorticoides y plasmaféresis para inducir la remisión incrementa la supervivencia a cinco años en $75 \%$ de los pacientes.

Palabras clave: Granulomatosis con poliangitis.

\footnotetext{
1 Jefe de la Unidad de Cuidados Intensivos.

2 Intensivista adscrito a la Unidad de Cuidados Intensivos.

3 Jefe del Servicio de Imagenología.
}

Hospital Ángeles León.

Correspondencia:

Dr. Alfonso García Luna

Correo electrónico: aglunaangelesleon@yahoo.com.mx

Aceptado: 09-10-2015.

Este artículo puede ser consultado en versión completa en http:// www.medigraphic.com/actamedica

\section{Summary}

Background: Granulomatosis with polyangiitis (Wegener's granulomatosis) is a rare, multisystem and autoimmune disease of unknown etiology. Its primary features include pauci-immune necrotizing granulomatous inflammation of small and medium vessel vasculitis; its prevalence is $1-9 / 100,000$ and the typical age of onset is between 35 and 55 years. As a multisystem disease, it can affect any area of the body, with predilection for the lungs and kidneys. Case report: 57-year-old female with one month of evolution characterized by clinical evidence of respiratory and renal failures requiring intubation and hemodialysis; she had a poor outcome upon her admission to the ICU, with positive c-ANCA. She was treated with rituximab, high doses of glucocorticoids and plasma exchange, achieving the recovery of her kidney and lung functions. Conclusions: Manifestations of granulomatosis with polyangiitis may occur in a fulminant way; $50 \%$ of chest imaging studies show cavitated nodules, which, coupled with crescentic necrotizing glomerulonephritis and the presence of c-ANCA (sensitivity of $96-98 \%$ ), support the diagnosis, which is confirmed by biopsy. Current treatment with rituximab, corticosteroids and plasma exchange to induce remission increases five-year survival in $75 \%$ of the patients.

Key words: Granulomatosis with polyangiitis.

\section{INTRODUCCIÓN}

La granulomatosis con poliangitis (GP), más conocida como granulomatosis de Wegener ${ }^{1}$ es una enfermedad rara, multisistémica, autoinmune, de etiología desconocida. Sus características primordiales incluyen inflamación granulomatosa necrosante y vasculitis pauciinmune de pequeños y medianos vasos. Su prevalencia es de 1 a 9/100,000 habitantes, siendo más común en descendientes del norte de Europa, con leve incremento en el género masculino (relación 1.5:1), teniendo el género femenino tendencia a enfermedad más limitada. Su edad típica de presentación es entre los 35 y 55 años. Como problema multisistémico, 
puede afectar a cualquier territorio de la economía, aunque tiene predilección por las vías aéreas y riñones. Al presentarse una paciente femenina de 57 años con evolución aguda caracterizada por insuficiencia respiratoria aunada a insuficiencia renal, la cual mostró mala evolución y requirió de hospitalización en la $\mathrm{UCl}$, en la que se efectuó el diagnóstico de granulomatosis con poliangitis, realizamos la presente comunicación, ya que no es frecuente que se diagnostique esta enfermedad directamente en una unidad de cuidados intensivos.

\section{CASO CLÍNICO}

Femenina de 57 años, diabética de cinco años de evolución, con control irregular a base de hipoglucemiantes orales (sitagliptina + metformina). Inició su padecimiento un mes antes de su ingreso con un cuadro caracterizado por ataque al estado general, fiebre no cuantificada, disnea inicialmente leve, tos escasa y congestión nasal. Se automanejó con sintomáticos, sin mejoría. La disnea pasó a ser de medianos esfuerzos y se agregó tos productiva, inicialmente con expectoración amarillenta y en ocasiones hemoptoica, por lo que acudió a un facultativo, quien inició manejo con ceftriaxona para el cuadro de infección de vías aéreas superiores, sin mejoría. Se agregaron al cuadro inicial náusea y vómito de características gastrobiliares. Cuatro días previos a su ingreso presentó disnea en reposo, por lo que acudió a la institución. A su llegada al servicio de urgencias, se encontró consciente, orientada en las tres esferas, con facies de angustia, regular estado de hidratación, palidez generalizada, TA 87/46 $\mathrm{mmHg}$, FC $84 x^{\prime}, \mathrm{FR} 24 x^{\prime}$, temperatura $36.0^{\circ} \mathrm{C}$; oximetría de pulso al aire ambiente de $82 \%$; presentó úlcera seca en el dorso del pie izquierdo, de cuatro meses de evolución. Se observaron estertores alveolares bilaterales de forma generalizada, predominando en las bases, no sibilancias; fue valorada por neumología, quien solicitó laboratorio y radiografía tele de tórax, que mostró infiltrados alveolares de tipo nodular en parches de aproximadamente cuatro centímetros, con distribución generalizada.

El laboratorio reportó citometría hemática con Hb 9.9 $\mathrm{g} / \mathrm{dL}$; hematocrito 28.3\%; eritrocitos $3.3410^{6} / \mu \mathrm{L} ; \mathrm{VCM} 85$ fL/L; HCM 29.6 pg; CMHC $34.8 \mathrm{~g} / \mathrm{dL}$; plaquetas 451,000 $\times 10^{3}$; leucocitosis de $12.7 \times 10^{3} / \mu \mathrm{L}$, con neutrofilia de $80 \%$, bandas $1 \%$, linfocitos $12 \%$, monocitos $3 \%$, basófilos 1\%; glucosa sanguínea $287 \mathrm{mg} / \mathrm{dL}$; BUN 88; urea $188 \mathrm{mg} /$ dL; ácido úrico 9.4 mg/dL; Na 129 mEq/L, K 4.6 mEq/L, Cl $98 \mathrm{mEq} / \mathrm{L}, \mathrm{Mg} 1.3 \mathrm{mEq} / \mathrm{L}, \mathrm{P} 6.5 \mathrm{mEq} / \mathrm{L}, \mathrm{Ca} 7.5 \mathrm{mEq} / \mathrm{L}$. El examen general de orina presentó aspecto amarillo, turbio; $\mathrm{pH}$ 5.0; densidad 1.015; glucosa negativa; proteínas 30 $\mathrm{mg} / \mathrm{dL}$; hemoglobina positiva +++ ; urobilinógeno normal; cuerpos cetónicos, bilirrubinas y nitritos negativos; en el sedimento urinario: leucocitos 70-80/campo, eritrocitos 40-50/campo, cristales negativos, cilindros ausentes; células epiteliales 10-15/campo, bacterias escasas, filamento mucoso escaso y levaduras (+). La tomografía axial computarizada de tórax exhibió infiltrados neumónicos bilaterales, difusos, inespecíficos, asociados a nódulos; algunos de ellos con imagen sugestiva de cavitación (Figuras 1 y 2). Los resultados de los exámenes de laboratorio complementarios indicaron BAAR negativo; PCR para TB negativa; dímero D $7.2 \mathrm{mg} / \mathrm{L}$; troponina T $0.31 \mu \mathrm{g} / \mathrm{L}$; procalcitonina $0.5 \mathrm{ng} / \mathrm{mL}$. La gasometría arterial: $\mathrm{pH}$ 7.33; $\mathrm{PaO}_{2} 43 \mathrm{mmHg} ; \mathrm{PaCO}_{2} 34$ $\mathrm{mmHg}$; HCO3 $17.9 \mathrm{mEq} / \mathrm{L}$; lactato $0.90 \mathrm{nmol} / \mathrm{L}$; saturación $75 \%$. Se tomaron muestras para cultivo secreción bronquial.

Se ingresó con los siguientes problemas médicos: a) insuficiencia respiratoria aguda tipo IA; b) bronconeumonía; c) anemia de origen a determinar; d) insuficiencia renal aguda; e) diabetes mellitus tipo II descompensada insulinorrequiriente y e) desequilibrio hidroelectrolítico. Se suspendió la sitagliptina por efectos indeseables de predisposición a infección de vías respiratorias altas y nasofaringitis.

Se inició un tratamiento médico con 1) omeprazol 40 mg IV cada 24 horas; 2) ertapenem 1 g IV cada 24 horas; 3) linezolid 600 mg IV cada 12 horas; 4) fluconazol 200 mg IV cada 24 horas; 5) paracetamol 1 g IV cada ocho horas por razón necesaria; 6) clorhidrato de ambroxol 1 ámpula IV cada ocho horas; 7) bumetanida 0.5 mg IV cada ocho horas; 8) deltaparina sódica 5,000 UI SC cada 24 horas y

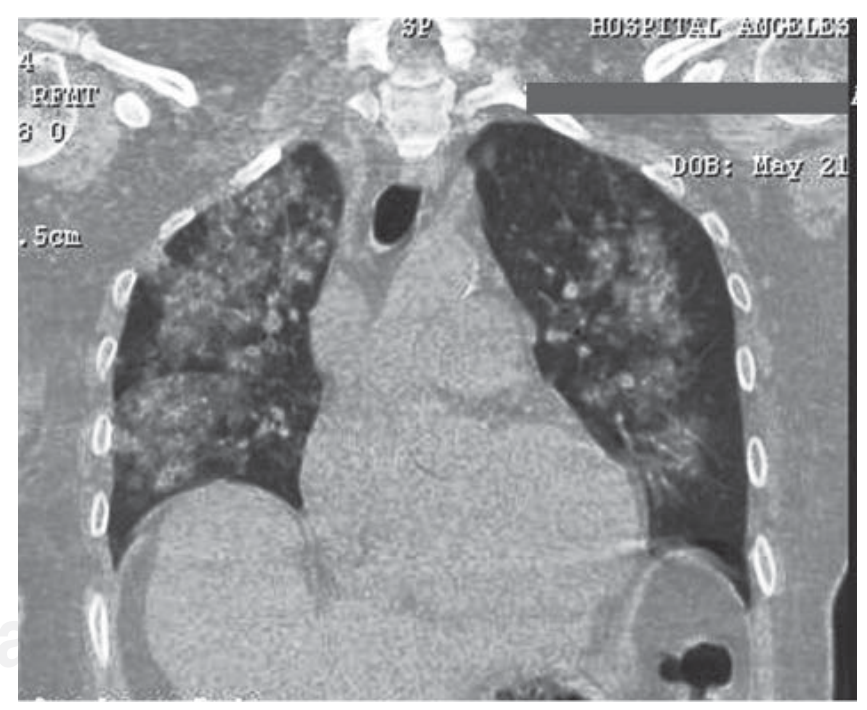

Figura 1. Tomografía axial computarizada con ventana para pulmón en corte coronal que muestra áreas de consolidación irregulares, redondeadas, bilaterales, de predominio peribronquial; pleura de espesor normal sin evidencia de líquido de derrame en femenina de 57 años con diagnóstico de granulomatosis con poliangitis. 
9) insulina rápida IV según requerimientos. Persistió con deterioro de la falla respiratoria y renal, con disminución importante de los volúmenes urinarios. Por ello, se solicitó interconsulta a nefrología, para complementar su evaluación y manejo. Se decidió iniciar con apoyo renal sustitutivo. A las 36 horas de su ingreso persistió con mala evolución y progresión rápida del deterioro tanto renal como respiratorio, por lo que se ingresó a la unidad de cuidados intensivos, requiriendo apoyo mecánico ventilatorio; continuó con terapia renal sustitutiva con hemodiálisis.

El cultivo de secreción bronquial mostró estreptococo alfa hemolítico escaso y Candida albicans. Se complementó el estudio con PCR, con resultados de $38 \mathrm{mg} / \mathrm{L}$ y velocidad de sedimentación globular con $71 \mathrm{~mm} / \mathrm{h}$. Ante la mala evolución y tomando en cuenta la no respuesta a antibióticos como paciente externa, el compromiso pulmonar con características nodulares, aunado al compromiso renal, los datos iniciales de vías aéreas superiores afectadas, la presencia de lesión dérmica (úlcera seca en el miembro inferior y la negatividad del BAAR y de la PCR para TB, las posibilidades diagnósticas se redujeron a: a) granulomatosis con poliangitis (síndrome de Wegener), b) síndrome de Goodpasture y c) vasculitis microangiopática. Por ello, se solicitaron anticuerpos citoplasmáticos antineutrófilos; se reportó por ELISA c-ANCA positivo, lo que apoyó el diagnóstico de granulomatosis con poliangitis. Por el mal estado general de la paciente, se optó por realizar una biopsia de mucosa nasal (Figura 3), que mostró tejido de granulación con necrosis fibrinoide en vasos de pequeño y mediano calibre, sin granulomas.

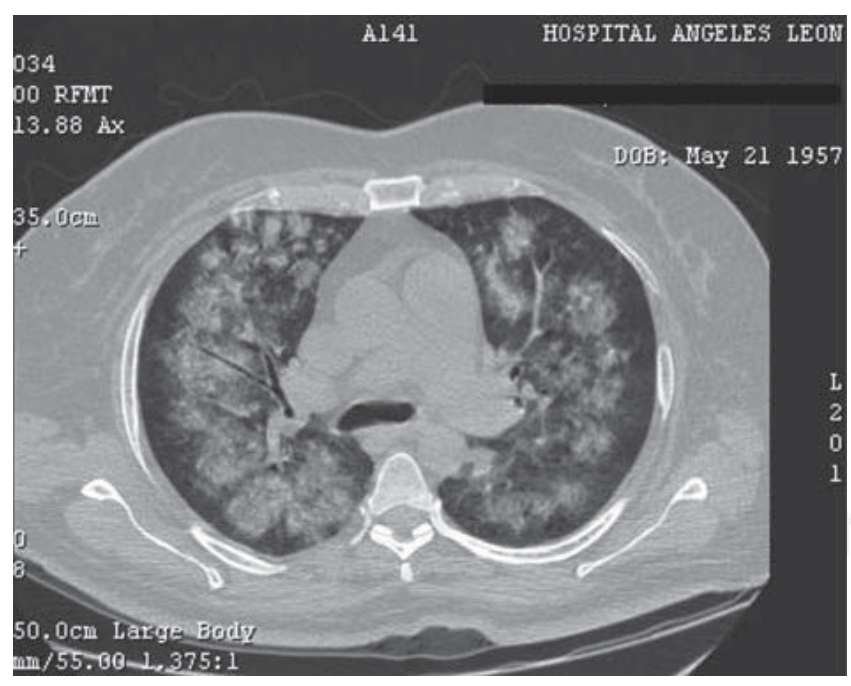

Figura 2. Tomografía axial computarizada con ventana para pulmón en corte axial que muestra áreas de consolidación irregulares, bilaterales, de predominio peribronquial; pleura de espesor normal.
Se decidió iniciar terapia inmunosupresora para inducción de remisión con I) metilprednisolona 500 mg IV cada 12 por 24 horas; posteriormente, II) prednisona $60 \mathrm{mg} /$ día, III) rituximab a dosis ajustada de $375 \mathrm{mg} / \mathrm{m}^{2} /$ semana y IV) plasmaféresis. A las 48 horas de iniciado el manejo anterior se observó mejoría franca en el patrón radiológico e intercambio gaseoso; se logró el retiro de la ventilación mecánica. Así mismo, se observó mejoría importante en los volúmenes urinarios y azoados, con lo que se consiguió suspender diuréticos de asa y se pudo espaciar la terapia renal sustitutiva. Con datos de franca mejoría, se dio de alta de la UCl y pasó a hospitalización, a control por reumatología.

\section{DISCUSIÓN}

La granulomatosis con poliangitis, más conocida como granulomatosis de Wegener (patólogo que la describió en 1936), es una enfermedad rara, multisistémica, autoinmune, de etiología desconocida. Sus características primordiales incluyen inflamación granulomatosa necrosante y vasculitis pauciinmune de pequeños y medianos vasos. Su prevalencia es de 1 a 9/100,000 habitantes; es más común en descendientes del norte de Europa (aproximadamente $90 \%$ ) y poco frecuente en población de color, con leve incremento en el género masculino (con relación 1.5:1); el género femenino tiene tendencia a enfermedad más limitada. Su inicio puede ser a cualquier edad, con edad típica de presentación entre los 35 y 55 años (el caso presentado ocurrió a los 57 años); es más rara en la infancia. ${ }^{2}$

El fenómeno inmunológico involucrado ${ }^{3}$ consiste en exposición de los neutrófilos a citocina, que suelen expresar a la proteinasa de serina y la mieloperoxidasa, siendo blanco

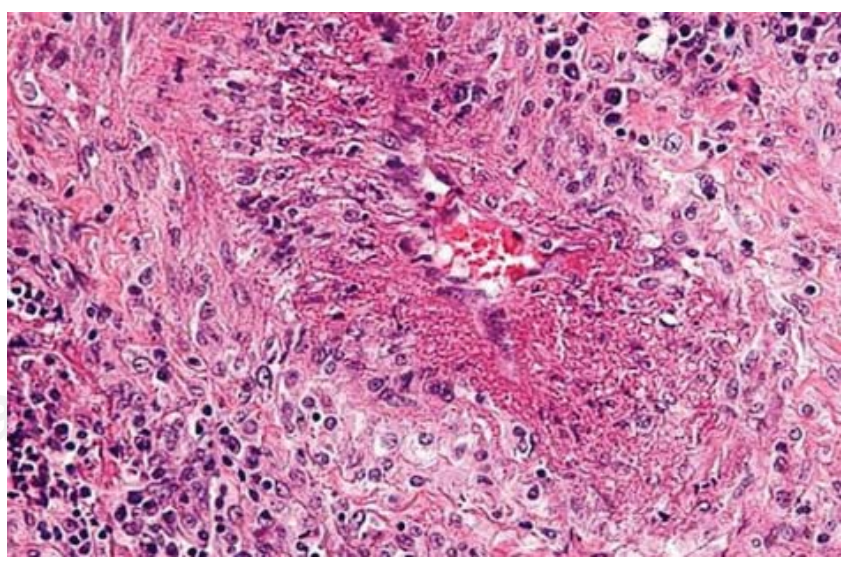

Figura 3. Biopsia de mucosa nasal, tinción hematoxilina y eosina a gran aumento, que muestra tejido de granulación con necrosis fibrinoide en vaso de pequeño calibre, sin granulomas. 
de los anticuerpos anticitoplasma del neutrófilo; estos se adhieren a las células endoteliales y las citocinas inducen la translocación de PR3 (proteinasa de serina 3) del citoplasma hacia la superficie de los neutrófilos, con lo que el endotelio vascular se ve involucrado, lo que se manifiesta como vasculitis por enzimas lisosomales y radicales libres de oxígeno.

Su espectro de presentación incluye infección respiratoria recurrente en adultos y problemas respiratorios de las vías aéreas superiores que responden mal al tratamiento convencional (como en el caso que presentamos). Los enfermos crónicos pueden tener manifestaciones generales no específicas, como fiebre, sudores nocturnos, fatiga, letargia y pérdida de peso; los síntomas oculares pueden ser conjuntivitis, epiescleritis, uveítis, vasculitis del nervio óptico, oclusión arterial retiniana, oclusión de las vías lagrimales y proptosis; puede haber alteraciones de oído, nariz y garganta, siendo la sinusitis crónica la manifestación inicial hasta en $67 \%$ de los casos (no estuvo presente en este). La pobre respuesta al tratamiento convencional (similar a la respuesta de nuestra paciente) debe hacer pensar en la posibilidad de GP. Otros signos otorrinolaringológicos son rinitis (en 22\%), epistaxis (en 15\%), deformidad en silla de montar del tabique nasal, pérdida de la audición por otitis media de tipo seroso, hiperplasia gingival en fresa y estridor laríngeo, que puede llegar a compromiso respiratorio por la presencia de granulomas traqueales o subglóticos.

La GP a nivel de vías respiratorias ${ }^{4}$ puede ser asintomática, de inicio insidioso, o severa y fulminante (como en el caso presentado); se manifiesta con infiltrados pulmonares en $71 \%$ de los casos, tos en $34 \%$, hemoptisis en $18 \%$, dolor torácico en $8 \%$, disnea en $7 \%$ (como en la paciente presentada, excepto por el dolor torácico); hemorragia alveolar difusa debido a capilaritis alveolar en cinco a $45 \%$ de los casos e, incluso, atelectasia.

Las manifestaciones clínicas musculoesqueléticas son mialgia, artralgia de carácter poliarticular, asimétrica, que afecta a las pequeñas y medianas articulaciones, y artritis que afecta a las grandes articulaciones; son raras las deformidades.

Desde el punto de vista renal, se caracteriza por glomerulonefritis necrosante en semilunas con sedimento urinario con más de cinco glóbulos rojos por campo (en nuestra enferma se reportaron 40-50 por campo) o cilindros de eritrocitos; la patología renal ocurre en $17 \%$ de los individuos al momento del diagnóstico y habitualmente es asintomática; la falla renal se puede observar en $11 \%$ de los casos al momento de la presentación (semejante a este reporte).

Las manifestaciones del sistema nervioso ${ }^{5}$ son neuropatía periférica hasta en $67 \%$ de los casos; típicamente, en la evolución a mediano plazo, incluye mononeuritis múltiple, polineuropatía sensitivomotora y parálisis de pares craneales; en el sistema nervioso central, al afectarse vasos de pequeño y mediano calibre, puede haber masas granulomatosas en el cerebro y médula espinal que involucran a órbita, nervio óptico, meninges y masa cerebral.

El tejido tegumentario puede afectarse de manera inespecífica; usualmente ocurre en las extremidades inferiores, con púrpura palpable o úlceras cutáneas (45\%) semejando el pioderma gangrenoso, presencia de petequias, vesículas, pústulas, bulas hemorrágicas, livedo reticularis, necrosis digital, hemorragias subungueales y úlceras genitales. En la paciente presentada, la úlcera seca en la extremidad inferior fue causada, a nuestro juicio, por la vasculitis más que por la microangiopatía que la diabetes mellitus origina, pues habitualmente se requiere de más tiempo de evolución en esta última).

Algunos hallazgos adicionales a nivel cardiaco son frote pericárdico, infarto al miocardio y muerte súbita. A nivel gastrointestinal, presencia de dolor abdominal relacionado con vasculitis esplácnica. Siendo la GPA una enfermedad sistémica, es una gran simuladora: el diagnóstico diferencial debe incluir, entre otras muchas enfermedades sistémicas, al síndrome de Churg-Strauss, la crioglobulinemia, el síndrome de Goodpasture, el síndrome urémico-hemolítico, la endocarditis infecciosa, la histiocitosis de células de Langerhans, la vasculitis leucocitoclástica, el absceso pulmonar y el cáncer pulmonar.

Dado que la GPA es un síndrome pulmonar y renal, deberá hacerse diagnóstico diferencial con el síndrome de Goodpasture (enfermedad caracterizada por anticuerpos contra la membrana basal). Este es mucho menos frecuente; sin embargo, los hallazgos son similares a los de la GPA. Se distingue porque en el síndrome de Goodpasture, clínicamente hay ausencia de anormalidades de las vías aéreas y existen anticuerpos antimembrana basal de los glomérulos, así como depósito de complejos inmunes en las biopsias renales.

Los exámenes de laboratorio de rutina no son específicos en la GPA; los resultados pueden incluir examen general de orina anormal, al igual que pruebas de la función renal; el factor reumatoide se muestra positivo a títulos bajos en dos tercios de los pacientes; la citometría hemática presenta anemia normocítica normocrómica en 50\% de los casos; la leucocitosis es común, con predominancia de neutrófilos; la velocidad de sedimentación globular y la proteína C pueden estar elevadas.

Los anticuerpos citoplasmáticos ${ }^{6}$ antineutrófilos (cANCA) dirigidos contra PR3 son la prueba más específica para GPA (en el presente caso fueron determinantes para el diagnóstico). Algunos pacientes expresan tinción perinuclear ANCA (p-ANCA) específicos para mieloperoxidasa; la combinación de pruebas por inmunofluorescencia y ELISA incrementa la sensibilidad y especificidad del diagnóstico de c-ANCA asociado a vasculitis de 96\% a 98.5\%, 
respectivamente. Debe recordarse que los c-ANCA pueden resultar positivos en poliangitis microscópica, policondritis recidivante y algunas glomerulonefritis.

Los estudios de gabinete útiles son la radiografía tele de tórax y la tomografía axial computarizada. Los hallazgos más comunes en la radiografías son nódulos simples o múltiples y la presencia de masas; los nódulos son típicamente difusos, siendo cavitados aproximadamente el 50\% (como en nuestra paciente); pueden ser detectadas opacidades difusas, atelectasia y neumonía obstructiva causadas por estenosis bronquial. Los hallazgos en la tomografía incluyen áreas de consolidación, opacidades en vidrio esmerilado parchadas, difusas o ambas; hallazgos adicionales son estenosis de la laringe o del árbol traqueobronquial, engrosamiento de la pared bronquial, bronquiectasias, derrame pleural y/o engrosamiento pleural y linfadenopatía. Otros estudios complementarios son la tomografía de senos paranasales, las pruebas pulmonares como espirometría, pletismografía y capacidad de difusión; la broncoscopia, que auxilia en la evaluación de la hemorragia alveolar, enfermedad de vías aéreas, infección y lesiones endobronquiales. El diagnóstico de GP es generalmente confirmado con biopsia de un sitio de enfermedad activa, ya sea renal o pulmonar.

El tratamiento está enfocado a la inducción de la remisión ${ }^{7}$ de la GP, que es el factor más importante en la etapa aguda. Se utiliza ciclosporina asociada a altas dosis de glucocorticoides, rituximab ${ }^{8}$ con altas dosis de glucocorticoides, metotrexate (oral o subcutáneo) con altas dosis de glucocorticoides (esta última en situaciones que no pongan en peligro la vida), así como plasmaféresis, ${ }^{9}$ la cual debe considerarse en personas con deterioro rápidamente progresivo de la enfermedad renal (niveles de creatinina mayores de $5.6 \mathrm{mg} / \mathrm{dL}$ ) para preservar la función renal. Con la terapia agresiva para enfermedad activa, más del $50 \%$ de los individuos recobran la función renal y son independientes de diálisis (como en el caso presentado). Una vez que la remisión se ha logrado, el tratamiento ${ }^{10}$ debe mantenerse al menos por 18 meses, siendo la azatioprina ( $2 \mathrm{mg} / \mathrm{kg} /$ día) tan segura como la ciclosporina para mantener la remisión; el metotrexate oral (20-25 mg/semana) ha sido utilizado para el mantenimiento de la remisión si los niveles de creatinina sérica son menores de $1.5 \mathrm{mg} / \mathrm{dL}$; la leflunamida (20-30 $\mathrm{mg} /$ día) es tan efectiva como el metotrexate, pero se asocia a mayores efectos adversos. La elevación de los títulos de c-ANCA correlaciona con la actividad de la enfermedad en dos tercios de los casos; sin embargo, resultados negativos de PR3 ANCA no necesariamente excluyen la posibilidad de recaída. La persistencia o reaparición de ANCA debe ser una indicación de incrementar la terapia.

Históricamente, los enfermos con GPA no tratada mostraban una supervivencia promedio de cinco meses después del diagnóstico, pues la mortalidad ${ }^{11}$ era del $90 \%$; la introducción de la corticoterapia prolongó la vida de estos pacientes a 7.5 meses. Con el advenimiento de la terapia citotóxica, la supervivencia mejoró de manera extraordinaria: de acuerdo a los metaanálisis efectuados, existen variaciones de 74 a 79\% de supervivencia a los cinco años; sin embargo, la mortalidad a un año sigue siendo elevada (11\%), con un rango de 2.2 . a $25 \%$ dependiendo de la severidad de la enfermedad y la intensidad del tratamiento. La infección, la insuficiencia respiratoria, la insuficiencia renal, la presencia de malignidad y los eventos cardiovasculares son las principales causas de muerte.

\section{CONCLUSIONES}

Las manifestaciones de granulomatosis con poliangitis pueden presentarse de manera fulminante. Los estudios de imagen de tórax con nódulos granulomatosos cavitados en $50 \%$, aunados a glomerulonefritis necrosante en semilunas y la presencia de c-ANCA apoyan el diagnóstico, que se confirma con biopsia. El tratamiento actual con rituximab, glucocorticoides y plasmaféresis para inducir la remisión incrementa la supervivencia a cinco años en $75 \%$ de los pacientes.

\section{REFERENCIAS}

1. Falk RJ, Gross WL, Guillevin L, Hoffman GS, Jayne DR, Jennette JC. Granulomatosis with polyangiitis (Wegener's): an alternative name for Wegener's granulomatosis. Arthritis Rheum. 2011; 63 (4): 863-864.

2. Hoffman GS, Kerr GS, Leavitt RY, Hallahan CW, Lebovics RS, Travis WD et al. Wegener granulomatosis: an analysis of 158 patients. Ann Intern Med. 1992; 116 (6): 488-498.

3. Kallenberg CG. Pathophysiology of ANCA-associated small vessel vasculitis. Curr Rheumatol Rep. 2010; 12: 399-405.

4. Manganelli P, Fietta P, Carotti M, Pesci A, Salaffi F. Respiratory system involvement in systemic vasculitis. Clin Exp Rheumatol. 2006; 24: S48-S59.

5. Holle JU, Gross WL. Neurological involvement in Wegener's granulomatosis. Curr Opin Rheumatol. 2011; 23: 7-11.

6. Mukhtyar C, Flossmann O, Hellmich B, Bacon P, Cid M, CohenTervaert JW et al. Outcomes from studies of antineutrophil cytoplasm antibody associated vasculitis: a systematic review by the European League Against Rheumatism systemic vasculitis task force. Ann Rheum Dis. 2008; 67: 1004-1010.

7. Specks U, Merkel PA, Seo P, Spiera R, Langford CA, Hoffman GS et al. Efficacy of remission-induction regimens for ANCA-associated vasculitis. N Engl J Med. 2013; 369 (5): 417-427.

8. Garcia-Valladares I, Espinoza LR. Is rituximab superior to cyclophosphamide for ANCA-associated vasculitis for induction of remission, and with a better safety profile? Curr Rheumatol Rep. 2010; 12: 395-398.

9. Jayne DR, Gaskin G, Rasmussen N, Abramowicz D, Ferrario F, Guillevin L et al. Randomized trial of plasma exchange or high-dosage methylprednisolone as adjunctive therapy for severe renal vasculitis. J Am Soc Nephrol. 2007; 18: 2180-2188.

10. Ntatsaki E, Carruthers D, Chakravarty K, D'Cruz D, Harper L, Jayne $D$ et al. BSR and BHPR guideline for the management of adults with ANCA-associated vasculitis. Rheumatology (Oxford). 2014; 53 (12): 2306-2309.

11. Phillip R, Luqmani R. Mortality in systemic vasculitis: a systematic review. Clin Exp Rheumatol. 2008; 26: S94-S104. 